\title{
Toric Intraocular Lens Implants for Astigmatism
}

\author{
Irene $\mathrm{C} \mathrm{KuO}^{1}$ and Victor E Reviglio 2
}

1. Associate Professor of Ophthalmology, Cornea and Refractive Surgery Services, Wilmer Eye Institute, Johns Hopkins University School of Medicine, Baltimore, Maryland, US; 2. Professor, Pathology Department, Cornea and Anterior Segment Research, Catholic University of Córdoba, School of Medicine, Ophthalmology Service, Córdoba Hospital and Instituto de la Visión Cerro de las Rosas, Sanatorio Allende, Córdoba, Argentina

\begin{abstract}
Toric intraocular lenses are available in our surgical armamentarium for use in cataract surgery, refractive lens exchange, phakic lens procedures and multifocal lens procedures. These lens implants enjoy a high level of success in terms of post-operative uncorrected visual acuity, astigmatism correction and safety. With time, toric phakic lens implants, not available worldwide, may gain popularity as more surgeons gain comfort and confidence in offering and performing an elective intraocular procedure.
\end{abstract}

\section{Keywords}

Toric, astigmatism, intraocular lens implant, phakic lens implant, toric

Disclosure: The authors have no conflicts of interest to declare.

Acknowledgement: Supported by an unrestricted grant from Research to Prevent Blindness, New York, US.

Received: 6 January 2012 Accepted: 23 February 2012 Citation: European Ophthalmic Review, 2012;6(3):164-8 DOI: 10.17925/EOR.2012.06.03.164

Correspondence: Irene C Kuo, Cornea and Refractive Surgery Services, Wilmer Eye Institute, 4924 Campbell Blvd. \#100, Baltimore, MD, 21236, US. E: ickuo@jhmi.edu

There are many options to treat corneal astigmatism in patients undergoing cataract surgery. This refractive error is found in $15-29 \%$ of prospective cataract patients. ${ }^{1-3}$ Astigmatic keratotomy at the time of surgery is one option, but although a powerful tool, such corneal relaxing incision has limited predictability and may result in overcorrection - especially in older patients or in patients with lower levels of astigmatism - or undercorrection in younger patients. Limbal relaxing incisions may have better predictability, but wound healing (and concomitant over- or undercorrection) can still be an issue.

Another option is to inform patients who choose a monofocal intraocular lens (IOL) that they can undergo excimer laser refractive surgery after cataract surgery in order to correct the anticipated residual corneal astigmatism.

A third option is to consider a toric IOL in patients with pre-operative and anticipated post-operative corneal astigmatism. First described in the ophthalmic peer-review literature in $1994,{ }^{4}$ toric IOLS are gaining popularity. The mechanics of small incision cataract extraction are unchanged and toric (monofocal) IOL implantation remains the same except for marking the proper axis on the cornea or limbus and implanting an IOL at that axis. Moreover, toric lens implants are no longer solely the purview of surgeons performing cataract surgery. This article will examine the option of toric IOLs to correct corneal astigmatism during cataract extraction, clear lens extraction, or as a phakic procedure.

\section{History and Overview}

One of the first reports in the literature of a toric IOL implant described results obtained with the Nidek NT-98B, a three-piece posterior chamber lens with an oval optic $(6.5 \times 5.5 \mathrm{~mm})$ and two positioning holes on its major axis. ${ }^{4}$ It had a toric correction on the concave posterior surface and the axis of cylinder lay on the minor axis of the lens. The anterior surface had a convex surface for implantation in eyes with against-the-rule corneal astigmatism. Therefore, the lens had to be positioned so that the line linking the positioning holes of the cylinder IOL (the lens axis) lay horizontally. From a review of the literature, this model is no longer available.

Many other toric lens implants have since been developed; in addition, toric multifocal and phakic toric lenses are now available. Early toric IOLS had a limited offering of toric powers (2.0 or 3.5 dioptres [D] at the IOL plane). The limited offering led to piggybacking of toric IOLs in patients with higher amounts of corneal astigmatism. ${ }^{5}$ The range of current toric IOL powers is higher. The Staar toric IOLS, while only offered in only two different diopters, can be positioned posteriorly, thereby reducing the power by $-0.2 \mathrm{D}$ and offering two additional corrective powers. The power of current toric IOLs can go up to $7.5 \mathrm{D}$ - this is the case, for example, in the Ophtec Artisan ${ }^{\circledR}$ toric phakic IOL, to be used in myopes or hyperopes - or even higher (12 D) - for example, in the AT Torbi $709 \mathrm{M}^{\circledR}$ (Carl Zeiss Meditec), a lens with bitoric design.

Current materials range from hydrophobic polysiloxane or silicone (Staar AA4203TF ${ }^{\circledR}$ [see Figure 1]) to hydrophobic acrylic (Hoya AF-1 $311^{\circledR}$, Alcon SN6AT3-9 ${ }^{\circledR}$ [see Figure 2]). Current models range from single-piece with loop haptics to plate silicone models (Staar, AT Torbi $709 \mathrm{M})$. In addition, the toric correction can be on the anterior surface of the optic (Staar), on the posterior surface of the optic (Alcon), or on both the anterior and posterior surfaces (AT Torbi 709M). A plate haptic lens made of hydrophilic acrylic with a hydrophobic surface, the AT Torbi 709M is the only monofocal bitoric IOL. It corrects 1 to $12 \mathrm{D}$ of cylinder in $0.5 \mathrm{D}$ increments.

The range of powers to correct astigmatism and the availability of the different makes of toric IOLs vary widely depending on geographic 


\section{Figure 1: Staar AA4203TF ${ }^{\circledR}$ Intraocular Lens}

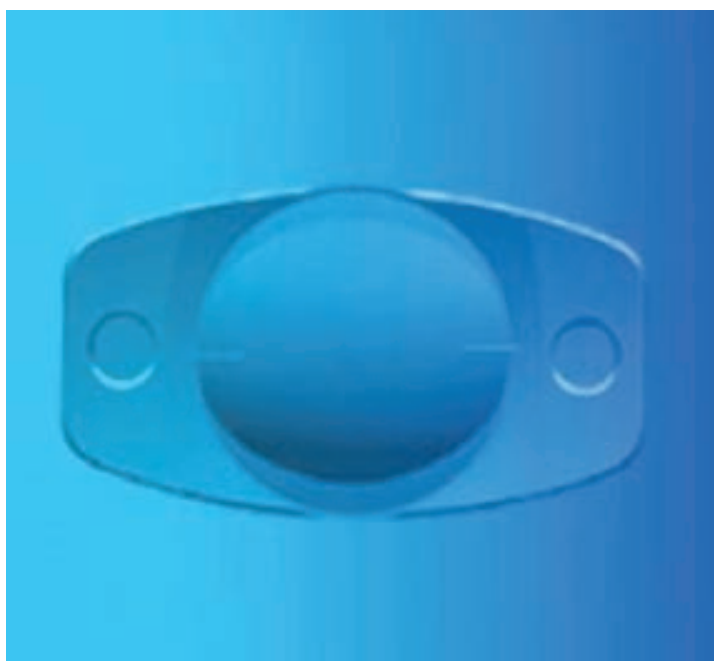

The Staar AA4203TF ${ }^{\circledR}$ model is a single-piece toric silicone intraocular lens (IOL) placed completely in the capsular bag. The lens is designed to correct 1.4 to $2.3 \mathrm{D}$ of corneal astigmatism during cataract surgery. There are two lens sizes. The $11.2 \mathrm{~mm}$ lens has large fenestrations to enhance post-operative fixation, which purportedly allow fibrous epithelial cells to migrate through the lens holes and assures optic centration and long-term stability. The larger-size lens also helps prevent rotation within the capsular bag.

\section{Figure 2: Alcon SN6AT3-9 ${ }^{\circledR}$ Intraocular Lens}

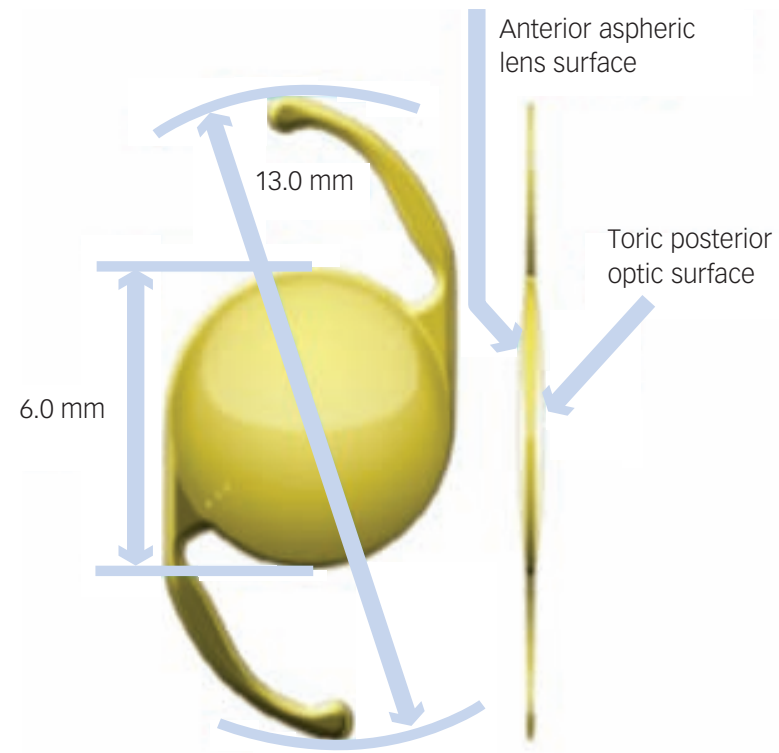

The Alcon SN6AT3-9 $9^{\circledR}$ model is a single-piece toric hydrophobic acrylic intraocular lens (IOL) intended for placement in the capsular bag. It possesses an anterior aspheric lens surface and a toric posterior optic surface. The lens is designed to correct 1.5 to $6 \mathrm{D}$ at the $10 \mathrm{~L}$ plane, corresponding to 1.0 to $4.1 \mathrm{D}$ at the corneal plane.

location. For example, in addition to the Alcon one-piece SN6A lens, the Alcon one-piece SN60 lens became available outside the US in powers ranging from T3 to T9, correcting up to $6 \mathrm{D}$ at the IOL plane (4.1 $\mathrm{D}$ at the corneal plane), after it had already been in use in Europe. The difference between the 60 and $6 \mathrm{~A}$ lenses became the spherical aberration in the latter.

Four toric multifocal IOL models are available:

- the diffractive AT Lisa 909M ${ }^{\circledR}$ IOL (Carl Zeiss Meditec - see Figure 3) with $+3.75 \mathrm{D}$ additional refractive power;
- the diffractive Acrysof IQ Restor ${ }^{\circledR}$ IOL (Alcon) with +3.00 D additional refractive power;

- the refractive M-flex ${ }^{\circledR}{ }^{\circledR} \mathrm{IOL}$ (Rayner Intraocular Lenses - see Figure 4) with +3.00 or $+4.00 \mathrm{D}$ additional refractive power; and

- the Lentis Mplus ${ }^{\circledR}$ IOL (Oculentis - see Figure 5) with +3.00 D sector-shaped near vision segment.

In general, reviews of the various toric IOLs have been favourable. In an earlier paper describing use of the Staar toric $1 \mathrm{OL}^{6}{ }^{6} 85 \%$ of eyes achieved uncorrected distance visual acuity (UDVA) of 20/40. In a study in 2011, $98 \%$ of eyes achieved UDVA of 20/40 or better with AT Lisa toric multifocal lens implant.? The goal of the latter paper was not solely to examine the UDVA near and intermediate outcomes, but also to report on patient satisfaction, including contrast sensitivity, spectacle dependence, glare, halos and starburst symptoms - the last three of which were found to be moderate in $50 \%$ of patients three months after surgery.

\section{Phakic Intraocular Lens Implantation}

Europe is the worldwide leader both in innovation in, and experience with, phakic IOLs. Phakic IOLs have several advantages over excimer laser refractive surgery. Primarily, phakic IOL implantation can be augmented or removed (with the goal of reversal of effect) in case of complications or failure, whereas laser refractive procedures are irreversible. Phakic IOLs also tend to produce higher levels of refractive correction.

However, the number of phakic IOL procedures remains relatively low compared with laser refractive surgery. Most likely, patients and surgeons are reluctant to embrace elective intraocular surgery, which, by definition, is more invasive than laser refractive surgery.

Nevertheless, the technology of phakic IOLs continues to evolve, with improving ease of implantation and decreasing risk of endothelial damage. Ophtec manufactures two phakic toric IOLs, Artisan ${ }^{\circledR}$ and Artiflex ${ }^{\circledR}$. These lenses are based on the same fixation method (iris enclavation) as the original lens designed by Jan Worst in 1978. The Artiflex phakic toric IOL corrects regular astigmatism in combination with myopia. The dioptric power range of the Artiflex lens includes a spherical correction from -1.0 to $-13.5 \mathrm{D}$ in combination with a cylinder correction from -1.0 to $-5.0 \mathrm{D}$. The optic material is hydrophobic polysiloxane, allowing insertion through a smaller incision than the Artisan phakic IOLS, which are made of polymethylmethacrylate.

The Artisan phakic toric IOLs are customised devices designed for the correction of regular astigmatism in combination with myopia or hyperopia. The asymmetric optic has two components: sphere and cylinder (see Figure 6). All (spherical) Artisan lenses for myopia and hyperopia can be supplied with cylinders between 1.0 and 7.5 D. There are also optics with only a cylindrical correction.

The Visian toric $\mathrm{ICL}^{\circledR}$ (implantable collamer lens), currently under review by the US Food and Drug Administration, is the toric version of the Visian ICL. It is sulcus-based and is designed to treat myopic patients (between -4.0 and -20 D) with astigmatism between 1 and 4 D.

\section{Pre-operative Evaluation of Patients}

In general, manual keratometry (Javal-Schiotz or Bausch and Lomb keratometer), which assesses the central $3 \mathrm{~mm}$ of the cornea, is recommended as part of the pre-operative evaluation. These 
keratometry readings are judged to be more reliable than those from corneal topography, IOL-Master ${ }^{\circledR}$ (Zeiss), Pentacam ${ }^{\circledR}$ (Oculus) or Orbscan ${ }^{\circledR}$ (Bausch \& Lomb) for assessing the steep and flat meridians and the power difference between the two. Topography by scheimpflug imaging or other is still, however, required to determine whether the astigmatism is regular or irregular. specifically, one is looking for conditions in the ectasia spectrum associated with irregular astigmatism, forme fruste keratoconus being the most common condition in this category. There have been case reports of toric and toric phakic IOLs being used in patients with keratoconus with good results. ${ }^{8-14}$ There has even been a case report ${ }^{15}$ of a bitoric lens being implanted in a patient with pellucid marginal degeneration and cataract, the high toric correction offered by the bitoric lens obviating use of piggybacked toric IOLS. When considering a toric IOL in a patient with a corneal ectasia or irregular corneal astigmatism, it is prudent to select a patient whose condition is stable. If the patient should require keratoplasty at a later date because the corneal condition is not stable, then having an implanted toric IOL would reduce his uncorrected visual acuity after such surgery and possibly worsen his (irregular) astigmatism

The pre-operative work-up for phakic IOL, toric or other, should include manifest refraction, cycloplegic refraction, UDVA, corrected distance visual acuity (CDVA), pupillometry, applanation tonometry to measure IOP, measurement of anterior chamber depth (ACD), measurement of sulcus-to-sulcus distance (which the measurement of 'white-to-white' approximates), corneal topography, pachymetry and central endothelial cell count. ${ }^{16}$ Generally, the recommended inclusion criteria for phakic IOL implantation include: age 21 years and older (with at least one manufacturer stating under 45 years of age); stable refraction for at least one year; iridocorneal angle $\geq 300$, central endothelial cell count as recommended by the manufacturer; and adequate anterior chamber depth (at least $3.00 \mathrm{~mm}$ according to one manufacturer) mesopic pupil size $<5.0-6.0 \mathrm{~mm}$. Exclusion criteria include: lack of anterior segment abnormality; recurrent or chronic uveitis; clinically significant cataract; glaucoma; pre-existing macular degeneration or macular pathology; and systemic conditions such as collagen vascular disease, diabetes or atopy.

\section{Marking the Eye}

The most common method of marking the eye in toric IOL procedures involves three steps. First, the surgeon places reference marks at the 3- and 9-o'clock meridians at the limbus or the cornea, either in the pre-operative area or in the operating theatre. This step should be done with the patient seated upright to avoid the effect of cyclotorsion when the patient moves to a supine position for the cataract procedure. Using the reference marks, the surgeon aligns a secondary device with the reference marks. Next, the surgeon uses the axis marks to delineate the steep axis of astigmatism upon which the IOL should be aligned. The surgeon then performs a standard capsulorhexis, hydrodissection and phacoemulsification. It is important to remove viscoelastic prior to rotating the IOL to the proper meridian; most surgeons recommend rotating the final 15-20 degrees under balanced salt solution. Another method is marking the limbus at 90 degrees and 180 degrees at the slit lamp before surgery. ${ }^{77}$ A newer method of marking the axis involves pre-operative slit-lamp photography to identify prominent vessels that will be used as markers. ${ }^{18}$

\section{Figure 3: Zeiss AT Lisa $909 \mathrm{M}^{\circledR}$ Intraocular Lens}

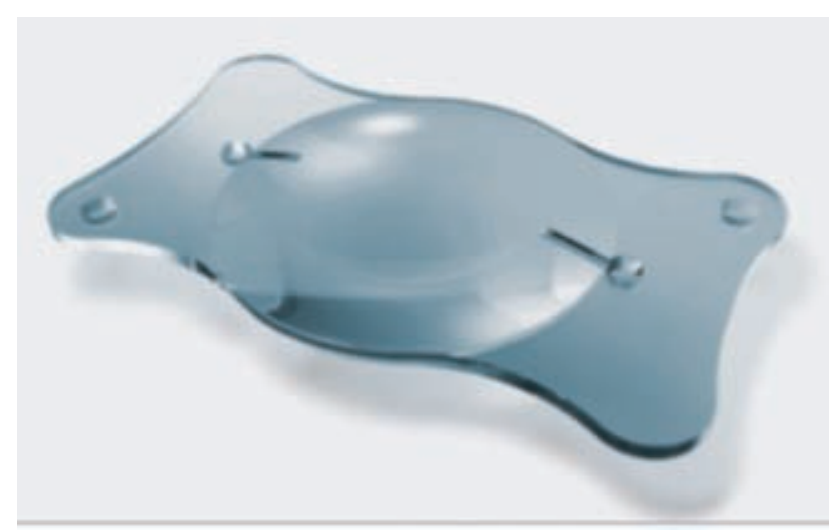

The Zeiss AT Lisa 909M ${ }^{\circledR}$ model (previously Acri.Lisa toric 466 TD) is a multifocal aspheric single-piece plate-haptic toric intraocular lens (IOL) made of hydrophilic acrylic with a hydrophobic surface. The toric component is on the anterior surface and the diffractive multifocal component is on the posterior surface. It can correct up to $12 \mathrm{D}$ of cylinder.

\section{Figure 4: Rayner M-flex ${ }^{\circledR}{ }^{\circledR}$ Intraocular Lens}

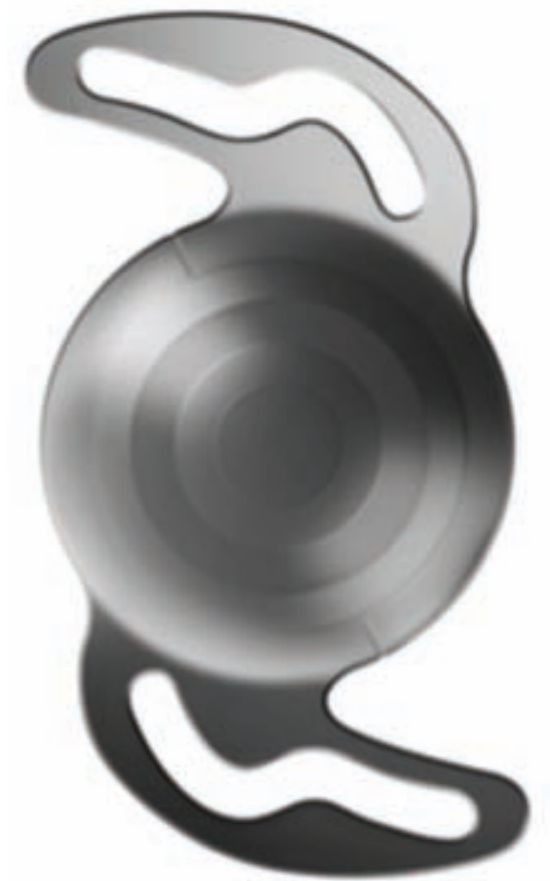

Rayner M-flex $T^{\circledR}$ intraocular lenses (IOLS) are based on multi-zoned refractive aspheric optic technology with either 4 or 5 annular zones (depending on base power) providing either +3.0 or $+4.0 \mathrm{D}$ of additional refractive power (equivalent to $+2.25 \mathrm{or}+3.0 \mathrm{D}$ at the spectacle plane).

\section{Analysing the Efficacy of Astigmatism Correction Procedures}

Surgically induced astigmatism must be included in any planning of astigmatism correction and any analysis of the efficacy of such correction (see Figure 7). Orienting the toric lens solely by using pre-operative keratometry or corneal topography to determine placement of the toric lens is incorrect because the cataract incision induces a small amount of cylinder. Because an axis or direction is involved, efficacy is more than just subtracting the absolute values of post-operative from pre-operative astigmatism. ${ }^{5}$

Although any surgery is truly a 3D procedure, most analyses of astigmatism correction are reduced to two dimensions. Two main 


\section{Figure 5: Oculentis Lentis Mplus ${ }^{\circledR}$ Intraocular Lens}
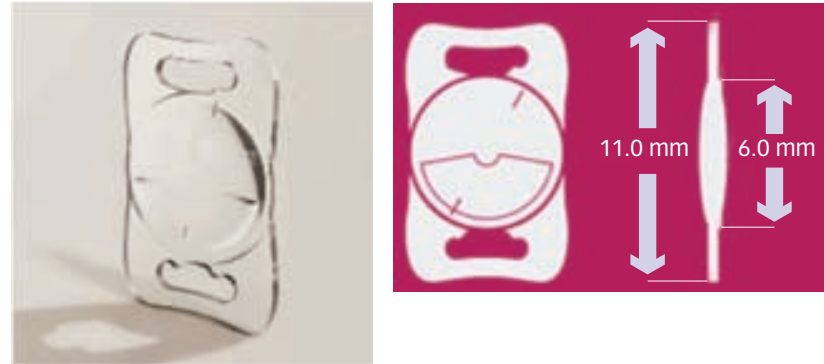

The Oculentis Lentis Mplus ${ }^{\circledR}$ model is a one-piece, posterior-chamber, multifocal toric acrylic intraocular lens with aspherical surface for capsular bag fixation and a posterior sector-shaped segment for near vision.

\section{Figure 6: Ophtec Artisan ${ }^{\circledR}$ Phakic Toric Intraocular Lens}

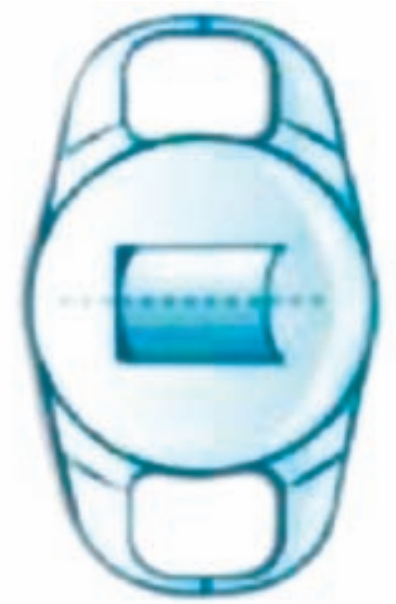

The asymmetric optic has two components: a sphere and a cylinder. All (spherical) Artisan lenses for myopia and hyperopia can be supplied with cylinders between 1 and 7.5 D. It is also possible to supply optics with only a cylindrical correction.

\section{Figure 7: Online Toric Calculators}
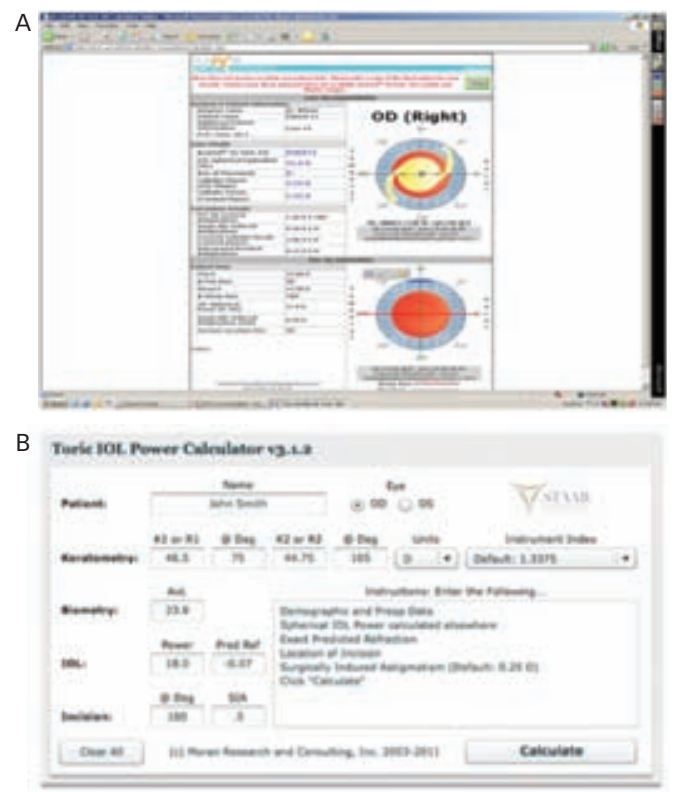

Two examples of online toric intraocular lens calculators, which help determine the axis at which the toric lens must be placed. The location of the surgeon's incision and surgically induced astigmatism are necessary entries in these calculators. types of analysis are available: vector and polar analyses. As astigmatism is expressed by a magnitude and direction, this can be converted into a vector and the change between pre-operative and post-operative astigmatism can be analysed using standard vector methods. The resultant vector can be then converted back into cylinder form. An alternative method of analysis involves converting the cylinder measurements into polar values. ${ }^{19}$ When the change between pre-operative and post-operative astigmatism is expressed in this way, the change in one polar value describes the magnitude of induced astigmatism while the change in the other value describes the rotation.

Several papers have compared results of one manufacturer's toric lens against those of another. One was a comparison of a surgeon's results with the Staar toric lens at one time period versus his results with the Alcon toric lens at a later period..$^{20,21} \mathrm{~A}$ more recent paper compared visual outcomes (IogMAR UCVA, IogMAR BSCVA), manifest cylinder power and astigmatism using the Visian toric ICL versus iris-fixated Artisan toric phakic intraocular lens. Results of the Visian toric ICL stabilised earlier than those of the Artisan lens, with an increase in cylinder power one month after surgery in the Artisan group. ${ }^{22}$

\section{Stability}

In one of the earliest reports of toric IOLS ${ }^{4}$ the authors indicated that rotation of less than 30 degrees appeared to be acceptable. We now know that each degree of error in alignment of a toric IOL reduces the cylinder power effect by approximately $3.3 \%,{ }^{23-24}$ more or less depending on whether it is a myopic or hyperopic correction, ${ }^{18}$ such that rotation by 30 degrees or more provides no correction for astigmatism and would actually induce further refractive error; the larger the degree of rotation, the greater the increase in astigmatism. ${ }^{25}$ When an IOL is off-axis one day after surgery, the question is whether the IOL rotated post-operatively or was placed off-axis during surgery. In some cases of reported IOL rotation, the problem may be cyclotorsion of the patient's eye or an intra-operative error in IOL placement along the proper axis. The earliest literature we could find on a toric IOL indicated that, by three months post-operatively, $25 \%$ of the 47 IOLs had rotated 20 degrees or more off-axis and $21 \%$ had rotated 30 or more. ${ }^{4}$ The rate of post-operative IOL repositioning was as high as $9.2 \%$ in another early paper describing results with a plate haptic toric $1 \mathrm{OL} .{ }^{6}$ A more recent paper describing one surgeon's consecutive implantation of 100 AcrySof SN60T toric IOLS showed that, at the final post-operative visit (between 4-6 weeks), $90 \%$ of IOLs were aligned within 5 degrees of the astigmatic axis and $99 \%$ were within 10 degrees of target; one case $(1.0 \%)$ was 15 degrees or more off-axis. ${ }^{20}$ None of the IOLS required surgical repositioning. ${ }^{20}$ The same surgeon described his results with the Staar toric lenses in a preceding study and found, in his series of 50 cases with the larger of the two Staar toric lenses, that no IOL needed to be repositioned. It appeared that the larger Staar toric lens offered more rotational stability than the smaller toric lens (only five cases). ${ }^{21}$ The IOL size relative to the capsular bag diameter is therefore of greater importance with toric than with non-toric IOLs. ${ }^{21}$ Similarly, favourable results with rotational stability have been reported for toric multifocal lenses. Three months post-operatively, the mean misalignment of toric multifocal IOLS implanted was 2.3+/-2.0 degrees (median 2.0 degrees; range 0 to 7 degrees). ${ }^{?}$ In three eyes, the misalignment was greater than 5 degrees $(6,6$, 7 degrees). No IOL was misaligned by 10 degrees or more. 
Some surgeons have recommended that, if repositioning of a plate haptic IOL is necessary, one should wait more than one week after the first operation, so that the lens capsule has an opportunity to fibrose and contract, thus increasing the chance that the IOL will stay in the intended position. ${ }^{25}$ This advice would likely be relevant to users of toric IOLs with loop haptics as well.

Some surgeons who would not otherwise suture their clear corneal wounds recommend suturing the wound in cases of toric IOL implantation to minimise the chance of post-operative IOL rotation, although again relative size of IOL to capsular bag (in pre-operative myopes, for example) may be more important.

\section{Summary}

Toric IOLs have evolved vastly since they were first described in 1994 There are now multifocal toric IOLs and phakic toric IOLs, in addition to standard toric IOLS. Both keratometry and corneal topography are necessary before surgery. Implantation along the proper axis and rotational stability are key to the success of toric IOL procedures. In the future, since toric IOLs are likely more expensive than standard IOLS and incur out-ofpocket expense for the patient, quality of life assessments (comparing against astigmatic patients who chose a standard monofocal lens), for example, will be important when evaluating the perceived success of these lenses - monofocal, multifocal or phakic - against standard monofocal lenses in patients with significant amounts of astigmatism.
1. Woodcock M, Shah, S, Smith RJ, Recent advances in customizing cataract surgery, BM, 2004:328:92-6.

Hoffer $\mathrm{KH}$, Biometry of 7,500 cataractous eyes, Am J Ophthalmol, 1980:90:360-8; correction 890.

3. Ninn-Pedersen K, Stenevi U, Ehinger B, Cataract patients in a defined Swedish population 1986-1990. 11: Preoperative observations, Acta Ophthalmol (Copenh), 1994: 72(1):10-5.

4. Shimizu K, Misawa A, Suzuki Y, Toric intraocular lenses: correcting astigmatism while controlling axis shift, J Cataract Refract Surg, 1994;20:523-6.

5. Gills JP, Treating astigmatism at the time of cataract surgery, Curr Opin Ophthalmol, 2002;13:2-6.

6. Sun X-Y, Vicary D, Montgomery P, Griffiths M, Toric intraocular lenses for correcting astigmatism in 130 eyes, ophthalmology, 2000:107:1776-82.

7. Visser N, Nuiijts RM, de Vries NE, Bauer NJC, Visual outcomes and patient satisfaction after cataract surgery with toric multifocal intraocular lens implantation, I Cataract Refract Surg, 2011;47:2034-42.

8. Navas A, Suárez R, One-year follow-up of toric intraocular lens implantation in forme fruste keratoconus, I Cataract Refract Surg, 2009;35(11):2024-7.

9. Kamiya K, Shimizu K, Ando W, et al., Phakic toric Implantable Collamer Lens implantation for the correction of high myopic astigmatism in eyes with keratoconus, I Refract Surg, 2008;24(8):840-2.
10. Alfonso JF, Fernández-Vega L, Lisa C, et al., Collagen copolyme toric posterior chamber phakic intraocular lens in eyes with keratoconus, I Cataract Refract Surg, 2010;36(6):906-16.

11. Kamiya K, Shimizu K, Kobashi H, et al., Clinical outcomes of posterior chamber toric phakic intraocular lens implantation for the correction of high myopic astigmatism in eyes with keratoconus: 6-month follow-up, Graefes Arch Clin Exp Ophthalmol, 2011;249(7):1073-80.

12. Sedaghat $M$, Ansari-Astaneh MR, Zarei-Ghanavati M, et al., Artisan iris-supported phakic IOL implantation in patients with keratoconus: a review of 16 eyes, $J$ Refract Surg, 2011;27(7):489-93.

13. Visser N, Gast ST, Bauer NJ, Nuijts RM, Cataract surgery with toric intraocular lens implantation in keratoconus: a case report, Cornea, 2011:30(6):720-3.

14. Jaimes M, Xacur-García F, Alvarez-Melloni D, et al, Refractive lens exchange with toric intraocular lenses in keratoconus, J Refract Surg, 2011;27(9):658-64.

15. Luck J, Customized ultra-high-power toric intraocular lens implantation for pellucid marginal degeneration and cataract, I Cataract Refract Surg, 2010;36:1235-8.

16. Guell JL, Morral M, Kook D, Kohnen T, Phakic intraocular lenses. Part 1: Historical overview, current models, selection criteria, and surgical techniques, Cataract Refract Surg, 2010;36:1976-93.

17. Carey PJ, Leccisotti A, McGilligan VE, et al., Assessment of toric intraocular lens alignment by a refractive power/corneal analyzer system and slitlamp observation, I Cataract Refract Surg, 2010;36(2):222-9.

18. Cha D, Kang SY, Kim SH, et al., New axis-marking method for a toric intraocular lens: mapping method, I Refract Surg, 2011;27(5):375-9.

19. Naeser K. Hiortdal I, Polar value analysis of refractive data, $\checkmark$ Cataract Refract Surg, 2001;27:86-94.

20. Chang DF, Comparative rotational stability of single-piece open-loop acrylic and plate-haptic silicone toric intraocular lenses, I Cataract Refract Surg, 2008;34(11):1842-7.

21. Chang DF, Early rotational stability of the longer Staar toric intraocular lens: fifty consecutive cases, I Cataract Refract Surg, 2003;29(5):935-40.

22. Lee SY, Kwon HJ, Ahn HS, et al., Comparison of patient outcomes after implantation of Visian toric implantable collamer lens and iris-fixated toric phakic intraocular lens, Eye, 2011;23:1409-17

23. Novis $\mathrm{C}$, Astigmatism and toric intraocular lenses, Curr Opin Ophthalmol, 2000;11:47-50

24. Ma JJK, Tseng SS, Simple method for accurate alignment of toric phakic and aphakic intraocular lens implantation, I Cataract Refract Surg, 2008; 34:1631-6.

25. Till JS, Yoder PR, Wilcox TK, Spielman JL, Toric intraocular lens implantation: 100 consecutive cases, I Cataract Refract Surg, 2002;28:295-301. 